\title{
COVID-19 control and preventive measures: a medico-legal analysis
}

\author{
Victor WT $\mathrm{Li}^{1}$ *, Trevor TW Wan² \\ ${ }^{1}$ Li Ka Shing Faculty of Medicine, The University of Hong Kong, Hong Kong \\ ${ }^{2}$ Faculty of Law, The University of Hong Kong, Hong Kong \\ *Corresponding author: u3548592@hku.hk
}

The coronavirus disease 2019 (COVID-19) pandemic has compelled governments around the world to deploy preventive and control measures of unprecedented stringency and scale. In Hong Kong, the Chief Executive-in-Council has invoked extensive powers under Section 8 of the Prevention and Control of Disease Ordinance (Cap 599) and adopted a series of subsidiary regulations in an attempt to control the spread of COVID-19.

Such extensive power is subject to judicial scrutiny using a four-stage proportionality inquiry tailored for evaluating whether rights and freedomsderogating laws and measures are consistent with the Basic Law and the Hong Kong Bill of Rights Ordinance (Cap 383). In the context of a public health emergency, it has to be shown that such laws and measures pursue legitimate aims that are required by the "exigencies of the public health situation" ${ }^{1}$ and are rationally connected to them. They should also be no more than reasonably necessary to achieve these aims without imposing an unacceptably harsh burden upon the individual.

Drawing upon the framework of the proportionality inquiry, we seek to explore the medical and constitutional justifications underlying three of such regulations: compulsory use of face masks, group gatherings ban, and compulsory testing for high-risk groups. Furthermore, we will comment on the potential mandatory use of the "LeaveHomeSafe" application in public facilities for contact tracing purposes, as well as compulsory vaccination for healthcare workers.

The use of face masks in public areas has been made compulsory under the Prevention and Control of Disease (Wearing of Mask) Regulation (Cap 599I). Use of face masks in conjunction with other social distancing measures reduces the risk of transmission of coronaviruses. ${ }^{2}$ This measure may be more useful in the current pandemic as pre-symptomatic and asymptomatic transmissions are common. ${ }^{3}$ Moreover, several local clusters have been associated with mask-off activities. ${ }^{4}$ In contrast with public backlash over wearing masks in other regions, Hong Kong has registered a significantly high level of selfcompliance reaching up to $97 \%,{ }^{5}$ which is attributed to lessons learnt from 2003 severe acute respiratory syndrome (SARS) outbreak. ${ }^{6}$ Critics of compulsory mask wearing consider it an encroachment on personal liberty. Nonetheless, flaws in this argument are apparent, as such encroachment is minimal and subject to regular review. Indeed, the High Court has held that Cap 599I "strikes a reasonable balance between (1) the societal benefits of the encroachment, and (2) the restriction of the [individual's] liberty".

The Prevention and Control of Disease (Prohibition on Group Gathering) Regulation (Cap 599G) imposes restriction on the permissible number of persons in public gatherings. In optimal settings, social distancing measures are associated with reduced risk of SARS-associated coronavirus 2 transmission. ${ }^{2}$ Nevertheless, restrictions on group gatherings are perceived to be antithetical to the freedoms of assembly and demonstration guaranteed by Article 27 of the Basic Law. Considering the high population density of Hong Kong, a rather broad list of exemptions available under Cap 599G, and regular reviews which resulted in relaxations previously, this regulation is arguably proportionate. However, discretion by authorised officers to disperse strictly unlawful group gatherings under section 10 of Cap 599G must be exercised reasonably and in good faith.

Compulsory testing of population at risk mandated by the Prevention and Control of Disease (Compulsory Testing for Certain Persons) Regulation (Cap 599J) has been a major measure used for tracing clusters of COVID-19 cases. Highrisk groups are identified and ordered to undergo testing, and this has been effective in limiting transmissions. ${ }^{8}$ However, this method is prone to recall bias (in which confirmed patients are unable to completely recall their close contacts) and may cause collateral effects (for example, the compulsory testing and quarantining of all residents in the whole building). Moreover, similar to criticisms made against Cap 599I and Cap 599G, although such interference is small given only highly specific groups are affected, the widespread deployment of Cap 599J powers may unduly interfere with personal freedoms and liberties. ${ }^{9,10}$

Insights derived above assist us in evaluating the potential mandatory use of the "LeaveHomeSafe" 
application in public facilities and compulsory vaccination of healthcare workers.

QR-code-based contact tracing is a key measure used by many countries, including mainland China and Singapore, which harnesses applications for tracking the location history of confirmed patients. ${ }^{11}$ In November 2020, the Hong Kong SAR Government launched the "LeaveHomeSafe" application which allows users to scan a QR code at designated locations on a voluntary basis in an attempt to record their location history. There are calls to make the use of this application compulsory. However, a survey shows that $48 \%$ of the respondents are against this. ${ }^{12}$ Distrust towards the government aside, concerns have been raised towards the potential breach of the right to privacy protected under the laws of Hong Kong.

Current reports on various types of SARS coronavirus 2 vaccines have shown heterogeneous immunogenicity and safety profiles. Yet, the keenness of Hong Kong and other regions and countries to secure vaccines for extensive vaccination programmes remains untrammelled. Among the general population, healthcare workers constitute a specific high-risk group due to their frequent exposure to patients and thereby an increased probability of being infected. ${ }^{13}$ This justifies their priority in being vaccinated. Nevertheless, distrust towards the government, coupled with heterogeneous results from clinical trials, may lower confidence amongst healthcare workers in getting vaccinated. ${ }^{14}$ This, however, does not justify making vaccination compulsory because this is likely to constitute a disproportionate interference with the right to privacy (ie, private life).

In summary, this commentary seeks to evaluate existing and potential COVID-19 control and preventive measures against medical and constitutional logics. Healthcare workers and the general population should be aware of the rationale behind these regulations and measures. Nevertheless, bearing in mind the importance of the rule of law, it remains crucial to strictly scrutinise further measures lest they impact upon individual rights and freedoms disproportionately. ${ }^{15}$

\section{Author contributions}

\section{Concept or design: All authors.}

Acquisition of data: VWT Li.

Analysis or interpretation of data: All authors.

Drafting of the manuscript: All authors.

Critical revision of the manuscript for important intellectual content: All authors.

All authors had full access to the data, contributed to the study, approved the final version for publication, and take responsibility for its accuracy and integrity.

\section{Conflicts of interest}

All authors have disclosed no conflicts of interest.

\section{Funding/support}

This commentary received no specific grant from any funding agency in the public, commercial, or not-for-profit sectors.

\section{References}

1. Human Rights Committee. International Covenant on Civil and Political Rights. United Nations. Statement on derogations from the Covenant in connection with the COVID-19 pandemic. 30 Apr 2020. Available from: https:// undocs.org/CCPR/C/128/2. Accessed 15 Dec 2020.

2. Chu DK, Akl EA, Duda S, et al. Physical distancing, face masks, and eye protection to prevent person-to-person transmission of SARS-CoV-2 and COVID-19: a systematic review and meta-analysis. Lancet 2020;395:1973-87.

3. Feng S, Shen C, Xia N, Song W, Fan M, Cowling BJ. Rational use of face masks in the COVID-19 pandemic. Lancet Respir Med 2020;8:434-6.

4. To KK, Yuen KY. Responding to COVID-19 in Hong Kong. Hong Kong Med J 2020;26:164-6.

5. Cheng VC, Wong SC, Chuang VW, et al. The role of community-wide wearing of face mask for control of coronavirus disease 2019 (COVID-19) epidemic due to SARS-CoV-2. J Infect 2020;81:107-14.

6. Hartley K, Jarvis DSL. Policymaking in a low-trust state: legitimacy, state capacity, and responses to COVID-19 in Hong Kong. Policy Soc 2020;39:403-23.

7. Haider Ali v. Social Welfare Department [2020] HKCFI 2611 [9].

8. Fisher D, Heymann D. Q\&A: The novel coronavirus outbreak causing COVID-19. BMC Med 2020;18:57.

9. Haffajee R, Parmet WE, Mello MM. What is a public health "emergency"? N Engl J Med 2014;371:986-8.

10. Ip EC. Hong Kong-the unprecedented promulgation of public health emergency regulations against the COVID-19 outbreak. Public Law 2020;2:580-2.

11. Huang $\mathrm{Y}, \mathrm{Wu} \mathrm{Q}$, Wang P, et al. Measures undertaken in china to avoid COVID-19 infection: internet-based, crosssectional survey study. J Med Internet Res 2020;22:e18718.

12. Hong Kong Public Opinion Research Institute. Community Democracy Project Research Report No. 48 "Community Health Module" Research Report No. 44 cum We Hongkongers Research Report No. 40. 2020;12. Available from: https://static1.squarespace. $\mathrm{com} /$ static/5cfd1ba6a7117c000170d7aa/t/5fd3108626 fa4758b5acaad0/1607667850435/Panel_report\%2351_ chi_2020dec11_PORI.pdf. Accessed 26 May 2021.

13. Russell FM, Greenwood B. Who should be prioritised for COVID-19 vaccination? Hum Vaccin Immunother 2021;17:1317-21.

14. Peiris M, Leung GM. What can we expect from firstgeneration COVID-19 vaccines? Lancet 2020;396:1467-9.

15. Thomson S, Ip EC. COVID-19 emergency measures and the impending authoritarian pandemic. J Law Biosci 2020;7:Isaa064. 